*Doutor em Direito Civil pela Pontifícia Universidade Católica de São Paulo (PUC-SP)

Professor efetivo de Direito na Universidade Federal do Espírito Santo (UFES) E-mail: contatoapb@, protonmail.com

**Mestrando em Direito Processual pela Universidade Federal do Espírito Santo (UFES)E-mail: tvilarinho@gmail. com

\section{Flexibilização do PRocedimento a PARTir DO TRÂNSITO DE TÉCNICAS PROCESSUAIS E SEUS FUNDAMENTOS: IMPLEMENTAÇÃO POR ADEQUAÇÃO JUDICIAL COMPULSÓRIA OU PELA VIA CONVENCIONAL?}

\section{Procedure FLEXIBILIZATION THROUGH TRANSPORT}

OF PROCESSUAL TECHNIQUES AND ITS LEGAL BASES: IMPLEMENTATION BY COMPULSORY JUDICIAL ADEQUACY OR THROUGH CONVENTIONAL MEANS?

\section{Augusto Passamani Bufulin* Tiago Aguiar Vilarinho**}

Como citar: BUFULIN, Augusto Passamani; VILARINHO, Tiago Aguiar. Flexibilização do procedimento a partir do trânsito de técnicas processuais e seus fundamentos: implementação por adequação judicial compulsória ou pela via convencional?. Scientia Iuris, Londrina, v. 25, n. 2, p. 187-204, jul. 2021. Doi: 10.5433/21788189.2021v25n2p187. ISSN: $2178-8189$.

Resumo: O presente estudo objetiva elucidar os fundamentos legais que indicam a possibilidade do livre trânsito de técnicas especiais entre os procedimentos e, a partir de tais constatações, examinar se o transporte poderia se efetivar a partir da denominada adequação judicial do procedimento, de forma compulsória. Objetiva-se investigar, outrossim, se o referido trânsito é passível de efetivação pela via convencional. Parte-se da premissa de que o CPC/2015 apresenta procedimento flexível e susceptível de melhor adaptação às contínuas transformações sociais; referida adaptação, no entanto, deve ocorrer com respaldo legal e constitucional, além de se submeter a critérios como a promoção de maior efetividade processual. Vale-se de pesquisa bibliográfica, com divisão do estudo em três seções primordiais. Inicia-se com a verificação da importância nas normas fundamentais do $\mathrm{CPC} / 2015$ para a compreensão de que o sistema por ele estruturado é flexível. Em seguida, analisam-se os negócios jurídicos processuais, seus sujeitos e limites e, por fim, parte-se à investigação do trânsito de técnicas processuais e a possibilidade de sua implementação a partir das adequações judicial e negocial do procedimento, concluindo-se pela preponderância da via negocial, inclusive proposta pelo próprio magistrado, como parte da avença.

Palavras-chave: flexibilização procedimental, trânsito de técnicas processuais, negócios jurídicos processuais, adequação do procedimento. 


\begin{abstract}
The present study aims to elucidate the legal foundations that indicate the possibility of free transit of special techniques between procedures and based on such findings, examines whether the transport could be effective from the so-called judicial adequacy of the procedure, in a compulsory manner. Its objective is to also investigate whether the transit can be carried out by conventional means. It is based on the premise that the $\mathrm{CPC} / 2015$ presents flexible procedure and is susceptible to better adaptation to continuous social changes; this adaptation, however, should occur with legal and constitutional support, in addition to submiting to criteria such as the promotion of greater procedural effectiveness. The study is based on bibliographical research and is divided into three main sections. It starts with the verification of the importance in the fundamental rules of the $\mathrm{CPC} / 2015$ for the understanding that the system structured by it is flexible. Then, it analyzes the procedural legal business, its subjects, and limits and, finally, it investigates the transit of procedural techniques and the possibility of its implementation from the judicial and negotiating adjustments of the procedure, concluding by the preponderance of the negotiating way, including those proposed by the judge himself, as part of the agreement.
\end{abstract}

Keywords: procedural flexibility, transit of procedural techniques, procedural negotiation, adequacy of the procedure. 


\section{INTRODUÇÃO}

Dentre os fatores que ensejaram a edição do Código de Processo Civil de 2015 - CPC/2015 -, elencam-se a necessidade de estruturação de um sistema processual mais rente às necessidades sociais ora vigentes, e a premência de tornar expressa a submissão do Código aos preceitos de ordem constitucional, mitigando-se o ainda arraigado paradigma de análise e interpretação das normas processuais a partir das bases em que forjado o diploma que lhe antecedeu - CPC/1973.

Tendo em conta tais objetivos, o legislador incorporou ao Código normas fundamentais de matiz constitucional, transmitindo a nítida mensagem de que a interpretação e a aplicação das normas processuais deverão ter como norte a Constituição Federal, especialmente os direitos e garantias previstos em seu art. $5^{\circ}$. Ademais, concebeu um procedimento consideravelmente mais flexível e apto a ser, por variados métodos, adaptado ao dinamismo das transformações sociais.

Nesse viés em que a adaptabilidade procedimental, a princípio, se mostra como ampla e passível de efetivação por mecanismos diversos, tem se propagado em doutrina a possibilidade de modulação procedimental a partir do livre trânsito de técnicas processuais entre ambientes legislativos distintos, com vistas a tutelar mais efetivamente o direito. Em sendo, de fato, possível tal trânsito, qual seria o seu fundamento e de que maneira ele seria mais adequadamente efetivado?

O presente estudo objetiva elucidar os fundamentos legais que indicam a possibilidade do livre trânsito de técnicas especiais entre os procedimentos e, a partir de tais constatações, examinar se o transporte poderia se efetivar a partir da denominada adequação judicial do procedimento, de forma compulsória. Objetiva-se investigar, outrossim, se o referido trânsito é passível de efetivação pela via convencional.

Parte-se da hipótese de que o sistema processual civil brasileiro comporta a adequação judicial impositiva apenas excepcionalmente, não parecendo, a priori, que a livre transposição de técnicas processuais se inclua nesse restrito campo de modulação por ato exclusivo do juiz. Por outro lado, a cooperação entre as partes, ou entre estas e o juiz, visando a modificação convencional do procedimento, a partir do transporte de técnicas processuais, se mostra em tese viável, desde que respeitados limites a serem adiante revelados.

As questões a serem tratadas se justificam a partir da compreensão de que a adaptabilidade do procedimento, embora ampla, deve se amparar nos limites impostos pelo próprio ordenamento e deve ser efetivada pelas vias que possuam respaldo legal e constitucional, sob pena de se verificarem, na prática, mudanças procedimentais estéreis ou que até obstaculizem o acesso à ordem jurídica justa, garantido em nossa Lei Maior.

Para responder a tais indagações, vale-se de pesquisa com objetivo exploratório e procedimento de levantamento bibliográfico, dividindo-se o trabalho em três seções principais.

Inicia-se a investigação a partir da verificação dos fundamentos que justificam a incorporação das normas fundamentais do processo civil e do papel de tais normas para a compreensão de que o atual Código é flexível. Adiante, introduz-se a temática dos negócios jurídicos processuais no ordenamento pátrio, com enfoque em seus sujeitos e limites, questões que subsidiam parte das conclusões adiante verificadas. Por fim, parte-se à análise do trânsito de 
técnicas processuais em nosso sistema e sua possibilidade de efetivação mediante as adequações judicial e convencional.

\section{FLEXIBILIZAÇÃO PROCEDIMENTAL: DA RIGIDEZ AO SISTEMA DE ADAPTABILIDADE ATÍPICA}

Desde que se iniciaram os debates em torno do Projeto de Lei que deu ensejo ao CPC/2015, parcela da doutrina passou a sustentar a ideia de que o sistema projetado para o Código é substancialmente mais vocacionado à maleabilidade procedimental do que a codificação que lhe antecedeu ${ }^{1}$. Assim, para os defensores de que o novel código se afastou do modelo rígido do CPC/1973, as indagações se voltaram mais para a aferição dos meios, contornos e limites da adaptabilidade procedimental do que propriamente para o estudo de sua positivação em nosso ordenamento processual.

Adere-se aqui ao posicionamento segundo o qual o atual diploma processual não apenas é flexível, como oferece técnicas variadas para a conformação do procedimento às especificidades do direito que se busca tutelar. Antes de se analisar os fundamentos que sustentam tal posição, importa compreender a importância das normas fundamentais do processo civil e como elas reforçam as conclusões no sentido de que o $\mathrm{CPC} / 2015$ introduziu um modelo aberto à maleabilidade procedimental.

\subsection{Razões que Justificam a Introdução das Normas Fundamentais do Processo Civil}

O CPC/2015 incorporou a necessidade de mudança de paradigma de análise do fenômeno processual que, paulatinamente, foi se consolidando desde a promulgação da Constituição da República de 1988, ao destinar, em seu Livro I da Parte Geral, Capítulo exclusivo fincando as normas fundamentais do processo civil, verdadeiros vetores para a interpretação e aplicação da legislação processual².

De uma detida análise das normas fundamentais do CPC/2015 é possível vislumbrar o inequívoco propósito legislativo de assentar que o processo civil deve ser analisado e interpretado sob a lente constitucional, com vistas à produção de uma decisão de mérito justa, tempestiva e que solucione a contenda com efetividade.

Grosso modo, boa parte das normas previstas no referido Capítulo reproduzem, expressa ou implicitamente, mandamentos constitucionais corolários do princípio do devido processo de direito, o que poderia levar o leitor desavisado à conclusão de que a repetição desses dispositivos, no bojo do CPC/2015, seria desnecessária. Contudo, a reprodução de dispositivos de essência constitucional e a preocupação do legislador em evidenciar a submissão da legislação processual à CFRB/88 se justificam em função do contexto que ensejou a elaboração da novel legislação.

1 Cf., por todos: Cunha (2013, p. 30) e Gajardoni (2011, p. 171), embora em trabalhos que se basearam no anteprojeto do CPC/2015.

2 Importante esclarecer que a escolha do termo "legislação processual": é que o CPC/2015 atua como tronco principal de todo o sistema processual, transportando suas normas para toda a legislação processual não codificada, conforme se evidencia da análise de seu art. 15 (MAZZEI; GONÇALVES, 2015). 
É que o digesto processual que lhe antecedeu foi forjado em circunstâncias deveras distintas das atuais, entendendo-se, naquele momento, pela necessidade de reforço dos valores segurança e previsibilidade jurídica, o que culminou com a elaboração de um Código que, malgrado apresentasse primor técnico-científico, imbuiu-se de um publicismo exacerbado e prestigiou em demasia o formalismo (NUNES, 2015). Ademais, primou pela concentração da gestão processual na figura do juiz, apresentando pouca maleabilidade procedimental (REDONDO, 2019). Como bem sintetiza Rodrigo Mazzei (2016, p. 59-60):

De fato, o Código de Processo Civil de 1973 - notadamente na sua redação original - está arraigado dos princípios do liberalismo, preso a uma concepção pouco social. Observe-se, por exemplo, que o Código de 1973 não mostra preocupação de calibre com o acesso à justiça e, muito pelo contrário, com raras exceções, opta por uma trilha em que o formalismo é colocado como farol de iluminação.

Por tais razões, o CPC/1973 se revelou improfícuo para se ajustar às transformações sociais que lhe sobrevieram, não tardando para que entrasse em descompasso com a realidade que objetivava regular e, por conseguinte, se tornasse inadequado à tutela eficiente e efetiva de direitos. Nada obstante, a obsolescência do CPC/1973, tal qual concebido, se tornou ainda mais contundente com o advento da Carta Política de 1988 e a cristalização de normas de matiz processual em seu rol de direitos e garantias fundamentais, alçadas ao status de cláusulas pétreas (RODRIGUES, 2015).

Não por acaso, nos anos que se seguiram à promulgação da CFRB/88, o CPC/1973 passou por inúmeras reformas destinadas a harmonizar o seu texto com os preceitos fundamentais constitucionais e, com isso, torná-lo apto a ensejar um acesso à ordem jurídica justa ${ }^{3}$, mediante o devido processo legal (MAZZEI, 2016).

Em que pese o esforço legislativo de compatibilização do CPC/1973 com o arcabouço de direitos e garantias constitucionais de cunho processual, mostrou-se de difícil sedimentação, no campo da aplicação do direito, a interpretação de seus dispositivos com espeque na carga axiológica que deflui da Lei Maior, talvez em função do já consolidado paradigma de análise do Código sob as lentes do regime e do contexto em que ele foi editado. E, como é de se imaginar, a tentativa de aprimoramento da legislação processual codificada para mais adequada e efetivamente assegurar a fruição de direitos pelo cidadão não alcançou resultados satisfatórios.

Daí decorre a importância de o CPC/2015, como diploma concebido que foi para instaurar verdadeira nova ordem processual, tê-lo feito com a consolidação, logo em seu primeiro Capítulo, de um rol de normas fundamentais repletas de valores constitucionais, tendo explicitado que a ordenação, disciplina e interpretação do Código deve se dar com olhos voltados à Constituição ${ }^{4}$.

3 Valendo-se aqui da expressão adotada por Kazuo Watanabe (2019) para definir o sentido contemporâneo do acesso à justiça, que não assegura apenas o ingresso formal nos órgãos do Poder Judiciário, mas a obtenção de uma tutela justa, tempestiva e que solucione efetivamente o conflito social.

4 Art. $1^{\circ}, \mathrm{CPC} / 2015$ : "O processo civil será ordenado, disciplinado e interpretado conforme os valores e as normas fundamentais estabelecidos na Constituição da República Federativa do Brasil, observando-se as disposições deste Código.” (BRASIL, 2015). 


\subsection{Da Abertura do Sistema à Adaptabilidade Procedimental}

Elucidadas, assim, as razões que orientaram a fixação das normas fundamentais no corpo do CPC/2015. Mas o caráter de deferência do atual Código para com a Carta de 1988 não se exaure na estipulação de normas fundamentais de cunho marcadamente constitucional. Da análise de seu texto é possível concluir pela sistematização de um modelo de processo ${ }^{5}$ deveras distinto do anterior, mais rente à realidade social vigente e melhor vocacionado a uma tutela efetiva e mais célere dos direitos fundamentais.

O Código de 2015 parece ter se afastado do (hiper)publicismo ${ }^{6}$ constatado no CPC/1973, na medida em que institui modelo policêntrico de processo, que constrange à necessidade de que todos os sujeitos que nele atuem cooperem para a solução célere, justa e efetiva da demanda (CÂMARA, 2016). Destaca-se, ainda, a amplificação das possibilidades de negociação processual típicas, assim como a previsão de cláusula geral de atipicidade de negociação para a disposição de situações jurídicas processuais ou redefinição do procedimento, o que evidencia um maior prestígio à vontade das partes na gestão dos rumos do processo.

Importante consignar que a atribuição de maior amplitude de participação das partes no processo, inclusive definindo o modo pelo qual se dará o seu desenvolvimento, não reflete um retorno ao modelo adversarial, característico de uma concepção privatística de processo (CABRAL, 2019). Trata-se, em verdade, de um reequilíbrio das funções dos sujeitos processuais, atribuindo-se às partes maiores condições de participação na construção dos caminhos para a solução do litígio, o que em tudo se conforma com a garantia do contraditório substancial, com o direito à liberdade e com o regime democrático (GRECO, 2008).

Nesse viés de prestígio à liberdade ${ }^{7}$ e participação das partes, ganha relevo a temática da adaptabilidade procedimental ${ }^{8}$ como método de potencialização da efetividade processual e do acesso à justiça, mediante reconfiguração do procedimento segundo as circunstâncias do litígio. Como bem assevera José Roberto dos Santos Bedaque (1995, p. 69): “Trata-se da concepção de um modelo procedimental flexível, passível de adaptação às circunstâncias apresentadas pela relação substancial. Não se admite mais o procedimento único, rígido, sem possibilidade de adequação às necessidades do caso concreto."

Pode-se dizer, portanto, regressando às normas fundamentais do processo civil, que a

5 Cláudio Madureira (2017) bem descreve os fundamentos do modelo de processo concebido pelo CPC/2015, assentando como nota distintiva essencial desse modelo a contenção da litigiosidade, a ser obtida mediante a reconfiguração da noção de contraditório, o prestígio à teoria dos precedentes e a reformulação da técnica de fundamentação das decisões judiciais.

6 Toma-se aqui a expressão utilizada por Bruno Garcia Redondo (2019) para dar ênfase ao caráter publicístico do processo em sua fase metodológica científica, como decorrência da necessidade de evidenciar a autonomia do direito processual em relação ao direito material, caráter que teria inspirado a elaboração dos Códigos de Processo Civil brasileiros de 1939 e 1973.

7 Sintetizando de maneira certeira a liberdade aplicada ao processo, Alois Troller (2009, p. 109): “Em uma relação técnica o processo nunca é mais bem ordenado do que quando se lhe pode conceder liberdade para servir ao direito material."

8 Trícia Navarro Xavier Cabral (2019, p. 40) identifica uma maior amplitude no termo flexibilização procedimental, que abarcaria "a possibilidade de modulação de regras preestabelecidas pelo legislador para se tentar um caminho que se adeque melhor ao caso concreto, seja otimizando etapas, seja construindo formatos procedimentais adaptáveis à solução da disputa judicial"'. 
adaptabilidade procedimental possui íntima relação com os comandos previstos nos arts. $3^{\circ}, 4^{\circ}$ e $6^{\circ}$ do $\mathrm{CPC} / 2015$, na medida em que amplifica as chances de que o acesso à justiça ocorra de maneira comparticipativa, justa e em tempo razoável.

Importa salientar que a adequação do procedimento pode se dar sob variadas perspectivas: a) no campo da produção legislativa, com o desenho de procedimentos diferenciados para cada direito que se busca tutelar; b) adequação judicial, decorrente do poder-dever conferido ao magistrado de ajuste do procedimento às especificidades do caso concreto ${ }^{9}$ e c) adequação convencional, fruto da celebração de negócios jurídicos processuais entre os sujeitos do processo (REDONDO, 2019).

Fixado o contexto de reequilíbrio entre o interesse público imanente ao processo e o interesse das partes na tutela de seus direitos, que ensejou a maior abertura à adaptabilidade procedimental no $\mathrm{CPC} / 2015$, indaga-se acerca da viabilidade do transporte de técnicas processuais já existentes na legislação, codificada ou não, para ambientes em que elas se mostrem úteis e efetivas à tutela do direito material. Em sendo possível tal transporte, seria lícito ao juiz impor a variação procedimental quando não requerida pelas partes ou a modificação do iter imprescinde da manifestação de vontade das partes plasmada em negócio processual?

Contudo, precede a abordagem destas questões uma digressão ao tema dos negócios jurídicos processuais no direito processual civil brasileiro, bem como de seus sujeitos e objeto (e a ainda árida definição de seus limites), questão de que se trata no item seguinte.

\section{NEGÓCIOS JURÍDICOS PROCESSUAIS: SUJEITOS E LIMITAÇÕES AO PODER DE AUTORREGRAMENTO DA VONTADE NO PROCESSO}

O negócio jurídico processual consiste em ato jurídico (lato sensu) alicerçado em manifestação de vontade do sujeito declarante, com repercussão processual (NOGUEIRA, 2020). Em síntese que reflete a concepção de negócio jurídico encampada em sua obra, Pedro Henrique Nogueira (2020, p. 175) define negócio jurídico processual como “[...] o fato jurídico voluntário em cujo suporte fático, descrito em norma processual, esteja conferido ao respectivo sujeito o poder de escolher a categoria jurídica ou estabelecer, dentre os limites fixados no próprio ordenamento jurídico, certas situações jurídicas processuais”. Refletem, portanto, a abertura de espaço para que a vontade dos sujeitos processuais produza os efeitos por eles almejados no processo, desde que alicerçados no ordenamento jurídico.

O CPC/2015, para além de estabelecer novas hipóteses típicas de negociação processual - p. ex. saneamento convencional do processo, distribuição convencional do ônus da prova -, consagrou em seu art. $190^{10}$ verdadeira cláusula geral de atipicidade da negociação processual, como decorrência do princípio do respeito ao autorregramento da vontade no processo civil, que

9 Veja-se que o próprio art. 139, VI, do CPC/2015, impõe expressamente ao magistrado a adequação procedimental conforme as necessidades do conflito de modo a conferir maior efetividade à tutela do direito.

10 Art. 190. "Versando o processo sobre direitos que admitam autocomposição, é lícito às partes plenamente capazes estipular mudanças no procedimento para ajustá-lo às especificidades da causa e convencionar sobre os seus ônus, poderes, faculdades e deveres processuais, antes ou durante o processo." (BRASIL, 2015). 
assegura às partes, dentro dos limites do ordenamento jurídico, o direito de regular seus interesses sem restrições indevidas (DIDIER JUNIOR, 2018).

Em conjunto com outros dispositivos do código ${ }^{11}$, a cláusula geral de atipicidade de negociação introduz, segundo Fredie Didier Junior (2018, p. 21), “[...] verdadeiro microssistema de proteção do exercício livre da vontade no processo", representando uma das facetas do direito fundamental à liberdade."

Pedro Henrique Nogueira (2020) estabelece interessante relação entre as normas fundamentais do CPC/2015 e os negócios jurídicos processuais atípicos, ao identificar as raízes do princípio do respeito ao autorregramento da vontade a partir da conjugação do art. $3^{\circ}$, $\S 2^{\circ}$ e $3^{\circ}$, do Código que dispõem, respectivamente, sobre o dever de o Estado promover, sempre que possível, a solução consensual dos conflitos e acerca da necessidade de que juízes, advogados, defensores públicos e membros do Ministério Público estimulem a utilização formas de tratamento adequado de conflitos $^{12}$. Veja-se, então, que a negociação processual atípica retrata uma dimensão da solução consensual de conflitos, na medida em que se permite aos sujeitos processuais a composição dirigida à disposição de situações jurídicas processuais ou ao ajuste do procedimento às especificidades da causa (CABRAL, 2019).

Note-se, diante desses traços característicos, que os negócios jurídicos processuais atípicos se inserem no contexto brevemente retratado linhas acima, de ampla maleabilidade procedimental promovida pelo $\mathrm{CPC} / 2015$, prestigiando-se inclusive a vontade das partes na construção consensual e cooperativa do trilho a ser percorrido para a tutela de seus interesses.

Mas será que só as partes poderiam figurar como sujeitos de convenções processuais? Ou será que o juiz, ou até mesmo terceiros e auxiliares da justiça seriam legitimados a integrar a dimensão subjetiva dos negócios jurídicos processuais? Perquire-se, outrossim, acerca dos requisitos de validade e dos limites que o ordenamento impõe ao poder de autorregramento da vontade no processo.

\subsection{Sujeitos dos Negócios Jurídicos Processuais}

Do próprio caput do art. 190 do CPC/2015, extrai-se que as partes são os sujeitos por excelência dos negócios jurídicos processuais. É a elas que é dado, com fulcro na cláusula geral de atipicidade de negociação, dispor de situações jurídicas processuais ou modular o procedimento conforme indiquem as especificidades da causa.

Inobstante, não se vislumbra como afastar o juiz da possibilidade de celebração de negócios jurídicos processuais, quando o próprio Código estabelece, em seu art. 191, a convenção típica de calendarização processual ${ }^{13}$, firmada entre o magistrado e as partes. Ao se debruçar sobre

11 Entre eles o art. 200: "Os atos das partes consistentes em declarações unilaterais ou bilaterais de vontade produzem imediatamente a constituição, modificação ou extinção de direitos processuais.” (BRASIL, 2015).

12 Rodrigo Mazzei e Bárbara Seccato Ruis Chagas (2018) enfrentam de maneira precisa a temática do tratamento adequado dos conflitos, partindo-se da premissa de que a promoção de um verdadeiro acesso à justiça exigiria do Estado não apenas a oferta de meios para o acesso ao Poder Judiciário, mas sim a estruturação de formas de tratamento de litígios que sejam capazes de lhes extrair o melhor e mais efetivo resultado para a sociedade.

13 Murilo Teixeira Avelino (2019) apresenta interessante construção no sentido de que a capacidade negocial do juiz não decorreria da cláusula geral do art. 190 do CPC/20215 - em cuja redação há unicamente menção às partes -, mas 
o tema dos negócios jurídicos processuais judiciais, Pedro Henrique Nogueira (2020) trata dos provimentos jurisdicionais como autênticos atos negociais, por meio dos quais o julgador pode efetivar a escolha de situações jurídicas processuais que impactarão na esfera das partes, o que evidencia ser imanente à própria atividade jurisdicional, em certa medida, o autorregramento da vontade.

Aliás, os negócios processuais atípicos que interfiram na esfera jurídica de prerrogativas e poderes-deveres do juiz, a seu turno, somente serão eficazes se contarem com a participação deste, seja integrando o ato desde a sua gênese, seja proferindo ato integrativo de sua eficácia homologação (CADIET, 2012).

Defende-se ainda, e com grande relevância para o que se discutirá adiante, que cabe ao juiz até mesmo propor às partes, sempre que identificar potencial de solução mais efetiva do litígio, a celebração de negócios jurídicos processuais para a reestruturação do procedimento, hipótese em que se encontrará diretamente vinculado ao que restar pactuado. Trata-se de desdobramento natural do dever de cooperação para a adequada promoção do acesso à justiça, previsto no art. $6^{\circ}$ do CPC/2015, assim como do princípio da adaptabilidade ou adequação processual.

Também não há óbice para que sujeitos que não integrem a relação processual em si participem de negócios jurídicos que produzam efeitos processuais, a exemplo dos auxiliares da justiça, membros do Ministério Público etc. Em síntese, como bem acentua Trícia Navarro Xavier Cabral (2019, p. 56), embora em análise focada na disponibilidade processual, que "[...] os atos de disposição podem, em princípio, ser praticados por todos os sujeitos processuais, ou seja, pessoas que sejam titulares de situações jurídicas ativas na relação jurídica processual, como as partes, os auxiliares da justiça e o juiz."

\subsection{Requisitos de Validade e Limites das Convenções Processuais Atípicas: Breves Considerações}

Um dos temas mais desafiantes, não obstante ainda pouco explorados, com sistematicidade, em relação aos negócios jurídicos processuais, diz respeito à definição dos limites do que pode ser convencionado pelas partes. Desde a promulgação do CPC/2015, observou-se a proliferação de estudos voltados à definição da natureza e elementos das convenções processuais, além da identificação de hipóteses de ajustes atípicos admissíveis na casuística. No entanto, são ainda relativamente escassos os trabalhos de fôlego que se dediquem especificamente ao estudo dos requisitos e limitações subjetivas e objetivas dos negócios processuais atípicos, que proporcionem bases mais sólidas para a atividade de controle judicial das convenções e, ainda, segurança para uma maior sedimentação do instituto na prática forense.

Pode-se retirar, já do caput e parágrafo único do art. 190, do CPC/2015, os parâmetros básicos a orientarem o controle de validade das convenções processuais atípicas.

De imediato se verifica que, não obstante o negócio jurídico processual seja independente da relação material e voltado à produção de efeitos no processo, o direito material que serve de

sim do princípio da adequação processual. 
pano de fundo ao litígio deverá ser passível de autocomposição. Neste ponto, a doutrina ressalta o primor técnico do legislador ao não baralhar os conceitos de direito indisponível e direito que admite ou não autocomposição, posto ser perfeitamente possível o direito material ostentar natureza indisponível e, ainda assim, ser suscetível à autocomposição (ainda que de forma parcial) (NEVES, 2018). No ponto, Bruno Garcia Redondo (2019) faz importante ressalva no sentido de que mesmo nas causas em que não se admita autocomposição, caso o negócio jurídico processual seja benéfico ao titular do direito protegido pela regra, não há razões para que não seja admitido pelo juiz. Afinal, deve-se ter em mente que o mote da alteração procedimental possibilitada pelo art. 190 é conferir maior efetividade à tutela jurisdicional, promovendo, assim, um melhor acesso à justiça.

O Código institui expressamente, no caput do art. 190, a necessidade de que as partes sejam capazes, tendo prevalecido em doutrina o entendimento de que a capacidade aí requerida é a processual (NOGUEIRA, 2020). Sendo processualmente capazes as partes ou estando eventual incapacidade devidamente suprida pela representação ou assistência, será válido o pacto.

Outra restrição que deflui do texto legal se relaciona à inserção do negócio jurídico processual, de maneira abusiva, em contratos de adesão. Veja-se que não é vedada a aposição de convenções processuais em contratos de adesão, mas sim a sua estipulação de maneira abusiva, notadamente quando visa a enfraquecer uma posição processual da parte aderente ou quando cria vantagens desproporcionais para a parte que formulou o instrumento contratual.

Tem-se, ainda de maneira expressa, a necessidade de que a parte celebrante não se encontre em situação de manifesta vulnerabilidade. Talvez seja esse o requisito explícito de validade mais sensível, dada a necessidade de análise casuística para a constatação da vulnerabilidade, que precisa ser manifesta e pode ostentar várias facetas (vulnerabilidades técnica, jurídica, científica, social etc.). Vale ressaltar, por oportuno, que a vulnerabilidade aqui tratada é aquela constatada no momento da celebração da avença e não a resultante do negócio, pois, perfeitamente possível a celebração de negócio jurídico processual de disposição de situação jurídica vantajosa, por exemplo, que em certa medida ensejará uma vulnerabilidade processual (REDONDO, 2019).

Admite-se que o dispositivo parece tomar como norte as vulnerabilidades técnica ou jurídica manifestas para que se afaste a aplicação da convenção, ou seja, somente deverá ser declarado inválido o ajuste se ficarem constatadas circunstâncias tais como a ausência de domínio da parte vulnerável acerca dos contornos do negócio ou ausência de assistência técnica por advogado em situações de elevada complexidade jurídica, por exemplo (NOGUEIRA, 2020).

Passando aos requisitos e limitações não expressos no CPC/2015, infere-se, de plano, que os negócios jurídicos processuais, em função de seu regime híbrido (direito material e processual), submeter-se-ão às prescrições do art. 104 do Código Civil, assim como deverão estar livres de vícios de vontade ou sociais, como o erro, dolo e a simulação.

Constituem ainda barreira em face da negociabilidade as normas processuais de natureza cogente, assim entendidas aquelas de ordem pública e que "[...] não abrem espaço para que seus destinatários convencionem qualquer prescrição que afaste - parcial ou totalmente - 
sua incidência.” (KLIPPEL, 2018, p. 70). Enfim, concluindo-se que a norma processual a ser eventualmente afastada pela negociação atípica tutela uma finalidade pública, deve o juiz negar aplicabilidade ao pacto neste particular (DIDIER JUNIOR, 2019).

Pode-se afirmar, sem maiores dificuldades, que as normas fundamentais do processo e os princípios processuais de natureza constitucional também servirão como limites das convenções processuais, não se admitindo a celebração de ajustes que afastem de maneira irrazoável ou desproporcional ${ }^{14}$ esses valores, notadamente se não se constatar, em contrapartida, a promoção do devido processo legal e do acesso substancial à justiça. Leonardo Greco (2008) resume o limite aqui tratado como observância à "ordem pública processual", que envolveria a observância dos subprincípios corolários do devido processo legal.

O tema dos requisitos e limites dos negócios jurídicos processuais desperta ainda diversos desdobramentos que fugiriam ao recorte do presente trabalho, mas, à guisa de conclusão do tópico, adverte-se, por conexão com o tema tratado no item seguinte - transporte convencional de técnicas processuais - para a necessidade de que as convenções dirigidas à alteração procedimental promovam idêntica, senão maior, efetividade para a tutela jurisdicional do que a técnica standard prevista para a hipótese, sob pena de se revelarem imprestáveis aos propósitos fundamentais do CPC/2015. Como bem observa Bruno Garcia Redondo (2019, p. 200), “[...] a adequação negocial atípica (sem especificação precisa, detalhada e clara do objeto por lei) não pode se basear em mero 'capricho' ou comodidade das partes, sem que haja justificativa democrática para que a norma legal (que é a regra geral) seja modificada."

\section{A ADAPTABILIDADE DO PROCEDIMENTO VIA TRANSPORTE DE TÉCNICAS PROCESSUAIS}

A flexibilidade procedimental permite maior liberdade para a formulação, supressão, incremento e remodelagem de atos procedimentais e técnicas processuais, sempre com vistas a tornar o procedimento mais rente à realidade material que o processo busca albergar.

É possível, no entanto, que a técnica ou procedimento diferenciado aptos a tornar mais efetivo o processo já exista no bojo do próprio Código ou até mesmo na legislação especial e extravagante, porém destinados a regular realidades distintas - ainda que, talvez, aproximadas.

$\mathrm{O}$ presente tópico se destina à análise de viabilidade do trânsito de técnicas processuais entre ambientes legislativos distintos. Verifica-se, outrossim, se o sistema processual civil comporta tal adequação por imposição do juiz, bem como a possibilidade de sua efetivação pela via negocial.

\subsection{O Trânsito de Técnicas Entre os Procedimentos}

$\mathrm{O}$ art. 327, $\S 2^{\circ}$, do CPC/2015, representou importante inovação no campo da adequação procedimental, ao prever a cumulação de pedidos a serem deduzidos em procedimentos distintos, desde que adotado o procedimento comum. E não é só: tal cumulação poderá ocorrer sem prejuízo

14 Veja-se a prescrição do art. $8^{\circ}$ do $\mathrm{CPC}$, norma fundamental do processo civil que induz à observância da razoabilidade e de proporcionalidade na aplicação do direito. 
da adoção de técnicas especiais previstas em procedimentos especiais, desde que sua aplicação seja compatível com as disposições do procedimento comum (PUPPIN; OLIVEIRA, 2017).

Fredie Didier Junior, Antonio do Passo Cabral e Leonardo Carneiro da Cunha (2020, p. 69-70) atribuem ao referido dispositivo a flexibilidade do procedimento comum, concluindo que “[...] ele é receptivo à incorporação, ainda que episódica, de técnicas diferenciadas pensadas para procedimentos especiais." O transporte de técnicas também pode ocorrer no sentido inverso, ou seja, do procedimento comum para os especiais, bem como entre procedimentos especiais, recursais ou executivos.

Rodrigo Mazzei e Tiago Figueiredo Gonçalves (2020), ao analisarem o processo de execução e o cumprimento de sentença como bases de importação e exportação de técnicas processuais, a partir de uma exegese destinada a conferir ao art. 771 do CPC/2015 a efetividade máxima que dele se possa extrair, fixam importantes premissas para que o transporte ocorra de forma compatível com o devido processo legal.

A primeira premissa digna de nota se refere à necessidade de análise de compatibilidade da técnica processual importada ou exportada com o ambiente em que ela irá produzir efeitos (MAZZEI; GONÇALVES, 2020). De fato, nem sempre a transposição de técnicas entre procedimentos ocorrerá de maneira totalmente compatível, pois as circunstâncias do direito material poderão ditar a inconveniência da aplicação de determinado dispositivo ou da prática de ato previsto na técnica transportada.

O segundo ponto de destaque, que se conecta a temas já tratados linhas acima, concerne ao sistema de aplicação interativa da legislação processual que se extrai da conjugação dos arts. 15 e 771 (caput e parágrafo único), ambos do CPC/2015. De uma rápida análise dos referidos dispositivos, poder-se-ia concluir que a aplicabilidade do processo de execução ao cumprimento de sentença, aos procedimentos especiais de execução e aos efeitos de atos ou fatos processuais aos quais a lei atribuir eficácia executiva e, noutro flanco, a transposição de regras do Livro I da Parte Especial do Código para a execução ocorrerão apenas em caráter subsidiário ou supletivo (leia-se: quando houver omissão ou incompletude). No entanto, em análise fincada na principiologia do CPC/2015, defendem Mazzei e Gonçalves (2020), com precisão, que a importação e exportação de técnicas desses ambientes ocorra de maneira recíproca, inclusive em substituição da técnica principal $^{15}$.

E a utilização da técnica exótica em lugar da principal exigirá, como se pode intuir, a constatação de incremento em efetividade para a tutela jurisdicional, ainda que, como já defendido, parcela da eficiência processual se comprometa. A análise de vantajosidade no sacrifício de parcela da eficiência processual em favor de um aprimoramento na solução do litígio dependerá da casuística e de um juízo de ponderação entre esses valores.

15 Note-se que neste caso não há omissão legislativa. A técnica padrão existe e se presta a regular suficientemente bem a realidade para a qual foi projetada. Ocorre que, a depender da situação, uma técnica "exótica" pode se mostrar mais efetiva para a maximização da proteção do direito material e, portanto, teria lugar em substituição à técnica principal. 


\subsection{Viabilidade do Transporte de Técnicas Processuais por Adequação Judicial}

A adaptação do procedimento promovida pelo juiz insere-se, como visto, entre os métodos de adequação usualmente identificados pela doutrina. Fernando da Fonseca Gajardoni (2007), ainda na vigência do CPC/1973, indicava ser possível a flexibilização procedimental pelo magistrado com vistas a conferir ao direito material a adequada tutela, ante a inconveniência de se aguardar a adequação pela via legislativa que, como se sabe, é incapaz de acompanhar a velocidade inerente às transformações sociais.

Embora reconhecendo a importância do rigor formal do processo e a necessidade de previsibilidade do procedimento para que a segurança jurídica se mantenha hígida, Gajardoni (2007) conclui que a submissão das alterações procedimentais intentadas pelo juiz ao contraditório garantiria às partes o conhecimento prévio do iter a ser trilhado. Além do contraditório prévio, as variações do procedimento standart previsto para o caso deverão ser precedidas de adequada fundamentação, até mesmo como forma de controle pelas instâncias recursais (GAJARDONI, 2007).

Pode-se resumir então, que os critérios básicos a nortearem a adequação procedimental, nos termos do que proposto por Gajardoni (2007), são: a) finalidade, entendida como a excepcionalidade da variação, que deverá ocorrer apenas para: a.1) garantir uma tutela adequada ao direito material, ante a insuficiência do procedimento predisposto; a.2) o descarte de formalidades ou atos desnecessários e a.3) promover condições mais isonômicas entre as partes e b) contraditório que garanta a efetiva participação das partes no convencimento do magistrado.

Nada obstante os substanciosos fundamentos acima apresentados, conclui-se que mesmo diante da considerável maleabilidade procedimental apresentada pelo CPC/2015 - sobretudo se comparado ao CPC/1973 - não há como concluir, de lege lata, pela possibilidade de adequação judicial via transporte de técnicas processuais entre ambientes legislativos distintos, ainda que submetida ao contraditório prévio.

Em relação à possibilidade de modulação do procedimento pelo juiz, parece ter o CPC/2015 a autorizado apenas para a dilatação de prazos e alteração da ordem de produção de provas; ainda assim, vinculadas tais alterações à obtenção de maior efetividade para a tutela do direito. Embora apresente-se como excepcionalmente possível a inversão da ordem de prática de atos processuais, desde que não resulte em prejuízo às partes, e o descarte de atos desnecessários, não se identifica previsão no sistema para que o juiz imponha às partes o percurso procedimental por trilho diverso do previsto em lei.

Situação distinta é aquela em que o magistrado, ao antever a utilidade de técnicas ou atos processuais previstos em procedimentos diversos para uma solução mais efetiva do caso sob análise, proponha às partes a celebração de negócio processual atípico para tal fim. Como antes visto, o juiz pode ser sujeito de negócio jurídico processual e, nesse viés, não se verifica barreira para que o magistrado possa propor a celebração de convenções voltadas à adaptabilidade procedimental, hipótese já defendida por Carlos Alberto Alvaro de Oliveira (1999, p. 66) mesmo 
sobre a vigência do CPC/1973:

[...] obtido o acordo das partes, e sempre que a tramitação processual prevista na lei não se adapte perfeitamente às exigências da demanda aforada, a possibilidade de amoldar o procedimento à especificidade da causa, por meio da prática de atos que melhor se prestem à apuração da verdade e acerto da decisão, prescindindo dos que se revelem inidôneos para o fim do processo.

O objeto da convenção - transporte de técnicas processuais entre procedimentos diversos -, a priori, é válido e encontra respaldo no art. 190 do CPC/2015. Obviamente, todos os requisitos de validade e parâmetros limitativos propostos linhas acima deverão ser observados, com a diferença de que, neste caso, o controle judicial se dará concomitantemente à formação do negócio.

Aincidência da consensualidade sobre a adequação procedimental proporciona a promoção não apenas da instrumentalidade da tutela jurisdicional, como também do regime democrático e da comparticipação.

Nesse cenário, identifica-se como momento propício à celebração de pactos procedimentais prevendo a importação de técnicas processuais, tendo como proponente o juiz, a fase de saneamento e organização do processo, que poderá inclusive ocorrer mediante a designação de audiência, nos termos do $\S 3^{\circ}$ do art. 337, CPC/2015. No saneamento processual, poderá desde já o magistrado ajustar com as partes o método de solução do conflito, importando mecanismos e atos (ou o modo de praticá-los) previstos originariamente para outras hipóteses, ficando os sujeitos do pacto, como visto, vinculados às declarações de vontade emitidas.

Assim, fora de um contexto convencional, não se afigura possível o juiz adequar o procedimento mediante transporte de técnicas processuais entre procedimentos distintos.

\subsection{Convenção Processual AtíPica de Importação de Técnicas Processuais}

A utilização de técnicas processuais originalmente previstas para ambientes diversos, quando não requerida pelas partes com base no art. $327, \S 2^{\circ}$, do CPC/2015 - cumulação objetiva -, poderá se efetivar a partir da celebração de negócio jurídico processual.

Poderão as partes, observados os limites do art. 190, CPC/2015, além de outros decorrentes do ordenamento jurídico, convencionar a importação de técnicas e atos processuais advindos de outros ambientes para a solução de suas controvérsias. Importante consignar que a convenção poderá ocorrer mesmo antes da litispendência, podendo constar como parte de um contrato, por exemplo.

As técnicas ou atos procedimentais, como já adiantado, poderão advir do próprio $\mathrm{CPC} / 2015$ (trecho de algum procedimento especial, por exemplo) ou da legislação não codificada (MAZZEI; GONÇALVES, 2020). Verificada a compatibilidade da técnica importada, a sua efetividade para melhor agasalhar o direito material em liça e, não estando presentes vícios que maculem o negócio jurídico processual atípico, será possível enxertá-la em lugar do procedimento padrão.

Importa ressalvar que a compatibilidade da técnica importada com o ambiente em que 
produzirá efeitos será facilitada quando se estiver diante de regras destinadas a tutelar situações materiais aproximadas. Seria o caso, por exemplo, de importação da regra prevista no inciso II, do art. 68, da Lei no 8.245/1991, que impõe a fixação de valor locatício provisório na ação revisional de aluguel. Tal mecanismo poderia ser instituído mediante negociação atípica para demandas revisionais de outras naturezas, impondo a fixação de um valor mais equânime desde o início da tramitação processual. Pode-se cogitar ainda de diálogo entre os procedimentos de insolvência civil e regras específicas previstas no processo falimentar. Ou, ainda, de convenção processual que empregue preceitos da ação civil pública nos procedimentos movidos em função da improbidade administrativa.

Enfim, o rol de técnicas passíveis de utilização efetiva em outros ambientes, mediante ajuste procedimental convencional, é bastante extenso, não se enquadrando nos limites do presente trabalho a enumeração das hipóteses, assunto a ser objeto de futuras investigações.

Vale alertar, em fechamento, que no caso de importação convencionada unicamente pelas partes, deverá o juiz se manifestar sobre a avença assim que dela tomar conhecimento, de maneira a desde logo conferir ao procedimento a previsibilidade que dele se espera. Nesta senda, entendendo o juiz pelo afastamento da convenção e preponderância do procedimento padrão, caberá impugnação via agravo de instrumento?

Pondo de lado o ainda vívido debate acerca da natureza do rol do art. 1.015 do CPC/2015 (se taxativo ou exemplificativo), pode-se dividir a questão da seguinte forma: a) decisão interlocutória que verse sobre convenção atípica de importação de técnicas no processo de execução ou cumprimento de sentença, hipótese em que caberá agravo de instrumento por força do parágrafo único do art. 1.015, CPC/2015 e b) decisão interlocutória que afaste a aplicação de negócio processual atípico de importação de técnicas processuais proferida em processo de conhecimento, hipótese para a qual não se vislumbra, de maneira direta, a recorribilidade via agravo de instrumento. Nada obstante, há quem sustente, como Bruno Garcia Redondo (2019) que, de maneira indireta, em interpretação analógica do disposto para a rejeição da convenção de arbitragem (art. 1.015, III, CPC/2015), seria a decisão recorrível mediante agravo de instrumento, posição a qual aqui se adere.

\section{CONCLUSÃO}

O CPC/2015 representou significativo avanço em termos de flexibilização não apenas do procedimento comum, como também dos procedimentos especiais, codificados ou não, considerando o caráter central do Código no sistema processual civil. Das normas fundamentais incorporadas pelo Código já se extrai a nítida preocupação do legislador com a estruturação de um processo adequado, eficiente, participativo, justo e efetivo, objetivos que somente serão plenamente atingidos, em certas situações, a partir da possibilidade de adaptação do procedimento ao dinamismo das relações sociais.

Da autorização para a cumulação objetiva nos termos no art. $327, \S 2^{\circ}$, do CPC/2015, exsurge a possibilidade de trânsito de técnicas processuais para aplicação em ambientes distintos 
daqueles para os quais foram forjadas.

Parcela da doutrina sustenta a viabilidade de adequação judicial do procedimento, com fundamento na necessidade de se amplificar o caráter instrumental do processo, tornando-o efetiva ferramenta para a tutela do direito material. Nada obstante reconheça-se a excepcional possibilidade de adequação do procedimento pelo magistrado, conclui-se que o sistema processual civil, tal qual concebido, apesar de flexível, não comporta a imposição pelo juiz de variações procedimentais com base no livre trânsito de técnicas processuais.

Nada obstante, identifica-se potencial para o juiz, responsável pela direção do processo, propor às partes a celebração de negócio jurídico processual voltado aos fins acima indicados, vinculando-se como sujeito do pacto. Nestes termos, dota-se a variação procedimental de maior segurança jurídica e respaldo legal.

Confirma-se, ainda, a possibilidade de que o transporte de técnicas processuais entre procedimentos distintos se efetive a partir da atividade negocial das partes, com posterior submissão da avença ao controle do juiz, que somente recusará aplicação ao negócio em caso de invalidade ou se identificados excessos na manifestação do poder de autorregramento da vontade no processo.

Como contribuição primordial dos resultados do estudo, aponta-se a revelação de novas frentes exploratórias que possuam como recorte a divisão de tarefas entre o magistrado e as partes, voltada à modulação negocial do procedimento. Como visto, o tema é bastante rico e carece ainda de futuras investigações que se proponham a identificar situações práticas em que o juiz ou as partes possam se valer do poder de autorregramento da vontade para mesclar técnicas processuais originárias de procedimentos distintos, codificados ou não.

Importante consignar, em fechamento, que independentemente da conjugação procedimental a ser proposta, sua implementação deverá ter como norte o incremento de efetividade da tutela jurisdicional, não se podendo conceber adequação improfícua do procedimento.

\section{REFERÊNCIAS}

AVELINO, Murilo Teixeira. A posição do magistrado em face dos negócios jurídicos processuais. In: CABRAL, Antonio do Passo; NOGUEIRA, Pedro Henrique (coord.). Negócios processuais. 4. ed. Salvador: JusPodivm, 2019. v. 1.

BEDAQUE, José Roberto dos Santos. Direito e processo: influência do direito material sobre o processo. São Paulo: Malheiros, 1995.

BRASIL. Lei no 13.105, de 16 de março de 2015. Código de Processo Civil. Brasília, DF: Presidência da República, 2015. Disponível em: http://www.planalto.gov.br/ccivil_03/_ato20152018/2015/lei/113105.htm. Acesso em: 29 dez. 2020.

CABRAL, Trícia Navarro Xavier. Limites da liberdade processual. Indaiatuba: Editora Foco, 2019.

CADIET, Löic. Los acuerdos procesales en derecho francés: situación actual de la contractualización del proceso y de la justicia en Francia. Civil Procedure Review, v. 3, n. 3, p. 03-35, ago./dez. 2012. 
CÂMARA, Alexandre Freitas. O novo processo civil brasileiro. 2. ed. São Paulo: Atlas, 2016.

CUNHA, Leonardo Carneiro da. Procedimento especial para as ações de família no projeto do novo Código de Processo Civil. In: FREIRE, Alexandre; DANTAS, Bruno; NUNES, Dierle; DIDIER JR., Fredie; MEDINA, José Miguel Garcia; FUX, Luiz; CAMARGO, Luiz Henrique Volpe; OLIVEIRA, Pedro Miranda de (org.). Novas tendências do processo civil: estudos sobre o projeto do novo Código de Processo Civil. Salvador: JusPodivm, 2013. v. 1.

DIDIER JUNIOR, Fredie. Ensaios sobre os negócios jurídicos processuais. Salvador: Juspodivm, 2018.

DIDIER JUNIOR, Fredie. Negócios jurídicos processuais no CPC-2015. In: CABRAL, Antonio do Passo; NOGUEIRA, Pedro Henrique (coord.). Negócios processuais. v. 1. 4. ed. Salvador: JusPodivm, 2019.

DIDIER JUNIOR, Fredie; CABRAL, Antonio do Passo; CUNHA, Leonardo Carneiro da. Por uma nova teoria dos procedimentos especiais: dos procedimentos às técnicas. 2. ed. Salvador: JusPodivm, 2020.

GAJARDONI, Fernando da Fonseca. Flexibilidade procedimental: um novo enfoque para o estudo do procedimento em matéria processual. 2007. Tese (Doutorado em Direito Processual) - Faculdade de Direito, Universidade de São Paulo, São Paulo, 2007.

GAJARDONI, Fernando da Fonseca. Procedimentos, déficit procedimental e flexibilização procedimental no novo CPC. Revista de Informação Legislativa, Brasília, v. 48, n. 190, p. 167177, abr./jun. 2011.

GRECO, Leonardo. Os atos de disposição processual - primeiras reflexões. In: MEDINA, José Miguel Garcia; CRUZ, Luana Pedrosa de Figueiredo; Cerqueira, Luís Otávio Sequeira de; GOMES JUNIOR, Luiz Manoel. Os poderes do juiz e o controle das decisões judiciais estudos em homenagem à Professora Teresa Arruda Alvim Wambier. São Paulo: RT, 2008.

KLIPPEL, Rodrigo. Teoria geral do processo \& teoria do processo civil brasileiro. Indaiatuba: Editora Foco, 2018.

MADUREIRA, Claudio. Fundamentos do novo processo civil brasileiro: o processo civil do formalismo-valorativo. Belo Horizonte: Fórum, 2017.

MAZZEI, Rodrigo. Breve história (ou estória) do Direito Processual Civil brasileiro: das Ordenações até a derrocada do Código de Processo Civil de 1973. In: DIDIER JUNIOR, Fredie; MACEDO, Lucas Buril de; PEIXOTO, Ravi; FREIRE, Alexandre (org.). Coleção novo CPC Doutrina Selecionada - Parte Geral. 2. ed. Salvador: Juspodivm, 2016. v. 1.

MAZZEI, Rodrigo; CHAGAS, Bárbara Seccato Ruis. Métodos ou tratamento adequados dos conflitos?. Revista Jurídica da Escola Superior de Advocacia da OAB-PR, Curitiba, v. 3. n. 1, p. 323-350, maio 2018.

MAZZEI, Rodrigo; GONÇALVES, Tiago Figueiredo. Visão geral dos procedimentos especiais. In: BUENO, Cassio Sarpinella (org.). Prodireito: Direito Processual Civil. Porto Alegre: Artmed Panamericana, 2015. v. 2 
MAZZEI, Rodrigo; GONÇALVES, Tiago Figueiredo. Ensaio sobre o processo de execução e o cumprimento da sentença como bases de importação e exportação no transporte de técnicas processuais. In: ASSIS, Araken de; BRUSCHI, Gilberto Gomes (coord.). Processo de execução e cumprimento de sentença: temas atuais e controvertidos. São Paulo: RT, 2020.

NEVES, Daniel Amorim Assumpção. Manual de direito processual civil. 10. ed. Salvador: Juspodivm, 2018.

NOGUEIRA, Pedro Henrique. Negócios jurídicos processuais. 4. ed. Salvador: Juspodivm, 2020 .

NUNES, Camila. Do Código Buzaid ao novo Código de Processo Civil: uma análise das influências culturais sofridas por ambas as codificações. Revista de Processo, São Paulo, v. 40, n. 246, p. 485-514, ago. 2015.

OLIVEIRA, Carlos Alberto Alvaro. Efetividade e processo de conhecimento. Revista de Processo, São Paulo, v. 96, p. 59-69, 1999.

PUPPIN, Bárbara Altoé; OLIVEIRA, Michelle Ivair Cavalcanti de. Breves apontamentos sobre o artigo $327 \S 2^{\circ}$ do CPC/2015. In: II Congresso de Processo Civil Internacional, Vitória. v.2., p. 281-289, 2017. Disponível em: https://www.periodicos.ufes.br/processocivilinternacional/issue/ view/860/454. Acesso em: 29 dez. 2020.

REDONDO, Bruno Garcia. Negócios jurídicos processuais atípicos no Direito Processual Civil brasileiro: existência, validade e eficácia. 2019. 304 f. Tese (Doutorado em Direito) Programa de Estudos Pós-Graduados em Direito, Pontifícia Universidade Católica de São Paulo, São Paulo, 2019.

RODRIGUES, Marcelo Abelha. O novo CPC e a tutela jurisdicional executiva (parte 1). Revista de Processo, São Paulo, v. 244, p. 87-150, jun. 2015.

TROLLER, Alois. Dos fundamentos do formalismo processual civil. Tradução de Carlos Alberto Alvaro de Oliveira. Porto Alegre: Sergio Antonio Fabris Editor, 2009.

WATANABE, Kazuo. Acesso à ordem jurídica justa (conceito atualizado de acesso à justiça): processo coletivo e outros estudos. Belo Horizonte: Del Rey, 2019.

Como citar: BUFULIN, Augusto Passamani; VILARINHO, Tiago Aguiar. Flexibilização do procedimento a partir do trânsito de técnicas processuais e seus fundamentos: implementação por adequação judicial compulsória ou pela via convencional?. Scientia Iuris, Londrina, v. 25, n. 2, p. 187-204, jul. 2021. Doi: 10.5433/21788189.2021v25n2p187. ISSN: 2178-8189.

Recebido em 07/04/2021

Aprovado em 08/07/2021 